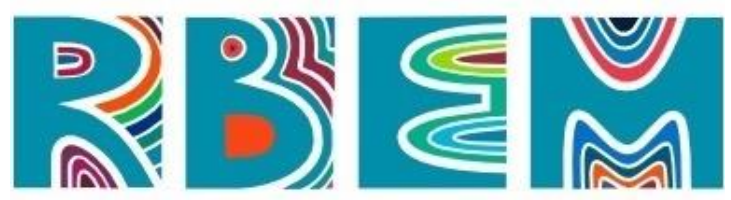

REVISTA BAIANA DE EDUCAÇÃO MATEMÁTICA

\title{
EDITORIAL
}

https://doi.org/10.47207/rbem.v2i01.13399

\section{Revista Baiana de Educação Matemática: Relatos de pesquisas e experiências que se desenvolveram em tempos de pandemia}

\author{
SILVA, Américo Junior Nunes da \\ Doutor em Educação pela Universidade Federal de São Carlos (UFSCar), professor do Departamento de \\ Educação da Universidade do Estado da Bahia, Campus VII, e do Programa de Mestrado em Educação, Cultura \\ e Territórios Semiáridos (PPGESA/UNEB). Orcid: https://orcid.org/0000-0002-7283-0367. E-mail: \\ ajnunes@uneb.br \\ VIEIRA, André Ricardo Lucas \\ Mestre em Educação de Jovens e Adultos pela Universidade do Estado da Bahia (MPEJA/UNEB), professor do \\ Instituto Federal de Educação, Ciência e Tecnologia do Sertão Pernambucano (IF Sertão-PE), Campus Santa \\ Maria da Boa Vista/PE. Orcid: https://orcid.org/0000-0002-9279-5802. E-mail: andre.ricardo@ifsertao-pe.edu.br
}

\section{Editorial}

Com grande alegria o volume dois da Revista Baiana de Educação Matemática foi publicado. Ainda vivenciando, em certa medida, o distanciamento social em virtude da pandemia do Novo Coronavírus, este espaço compartilha com seus leitores resultados de investigações científicas realizadas no campo da Educação Matemática.

É nesta perspectiva que compreendemos que o debate científico que será suscitado a partir dos textos aqui publicados possibilitará a construção de novos conhecimentos para a área da Educação Matemática. Para além disso, os artigos que compõem este volume tiveram como foco o professor que ensina Matemática, sua formação, a realidade e cultura escolar e o ensino e aprendizagem dessa ciência evidenciando uma pluralidade de referenciais teóricos e metodológicos que contribuem para, na nossa área, o fortalecimento da pesquisa.

Vale ressaltar ainda que ao longo deste ano publicamos um dossiê temático intitulado O Estágio Curricular Supervisionado em Matemática nos contextos de ensino presencial, remoto e híbrido que foi organizado pelo Prof. Dr. Dario Fiorentini da Universidade Estadual de Campinas (UNICAMP), Prof. ${ }^{a}$ Dr. ${ }^{a}$ Regina da Silva Pina Neves da Universidade de Brasília (UnB) e pela Prof. ${ }^{a}$ Dr. $^{a}$ Maria Dalvirene Braga, também da Universidade de Brasília (UnB). Esse trabalho contou ainda com o auxílio do editor chefe 


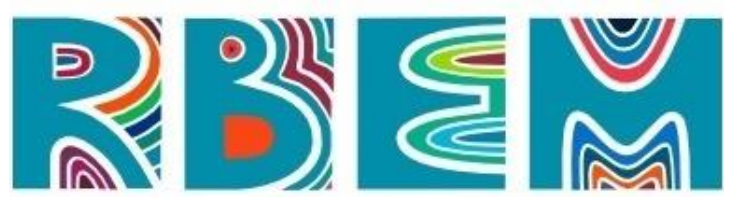

REVISTA BAIANA DE EDUCAÇÃO MATEMÁTICA

desta revista, o Prof. Dr. Américo Junior Nunes da Silva e o editor assistente Prof. Me. André Ricardo Lucas Vieira.

Fiorentini et al (2021, p. 01) destacam no editorial que "o dossiê temático teve como objeto de estudo o Estágio Curricular Supervisionado em Matemática. O referido dossiê teve seu desenvolvimento em diferentes contextos de ensino presencial, remoto e híbrido, totalizando 26 trabalhos, sendo dezenove (19) Artigos e sete (07) Relatos de Experiência. Esses estudos foram produzidos por pesquisadores e pesquisadoras de instituições públicas e privadas, provenientes de todas as regiões do país".

No que tange ao fluxo contínuo da revista, publicamos oito (08) Artigos e (01) Relato de Experiência. O primeiro texto, intitulado "Influências do Estágio Supervisionado para professores de Matemática em início de carreira", busca compreender escolhas e características das escolas-campo. De autoria de Ulisses Dias da Silva e Ana Teresa de Carvalho Correa de Oliveira, se propõe a investigar as influências do estágio curricular supervisionado obrigatório para professores no início de suas carreiras. Esta pesquisa, que é um recorte de uma tese de doutorado, foi desenvolvida com vinte sujeitos e organizada em seis categorias, a saber: a escola, o estágio acontecendo, as relações construídas, os sentidos construídos pelos sujeitos e o passado no presente. Os autores destacam que os estágios divergem significativamente de instituição para instituição. Apontam que as escolas-campo mais preparadas e com maior acompanhamento possuem impactos mais significativos. E por fim, afirmam que é preciso investir em uma maior integração do estágio ao currículo da licenciatura para melhores resultados formativos.

Clarissa Raimundo de Ataide e Walber Christiano Lima da Costa objetivaram no texto, intitulado "Formação de Professores: o estado do conhecimento no ensino de fração para estudantes surdos", conhecer o panorama das pesquisas que trazem a formação de professores para o ensino de fração com estudantes surdos. Os autores apontam para a utilização da Língua Brasileira de Sinais (Libras) como um fator importante no ensino de fração no contexto dos anos iniciais dos estudantes surdos, visando à inclusão deste público.

"Entendimentos de professores que ensinam matemática sobre a relação entre jogo e raciocínio lógico", terceiro artigo deste volume e de autoria das professoras Renaura Matos de Souza e Ilvanete dos Santos de Souza e do professor Reinaldo Feio Lima, buscou responder ao questionamento de como professores que ensinam matemática, nos Anos Finais 


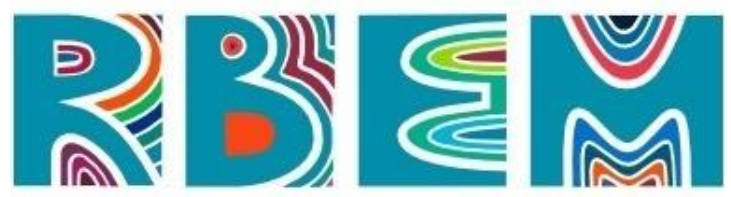

REVISTA BAIANA DE EDUCAÇÃO MATEMÁTICA

do Ensino Fundamental, na rede municipal de Barreiras-BA, entendem os jogos matemáticos como instrumento de desenvolvimento do raciocínio lógico. Neste sentido, os autores destacam que foram abordadas questões que remetem ao ensino de matemática e relacionadas às dificuldades recorrentemente encontradas no processo de ensino e aprendizagem, as práticas metodológicas adotadas em suas aulas, o conceito de jogo e raciocínio lógico, dentre outros.

O quarto texto "Depoimentos de alunos concluintes de uma licenciatura sobre o processo de ensino e aprendizagem", de autoria de Pedro Lucio Barboza, investiga as concepções de alunos concluintes de um curso de licenciatura em matemática sobre o processo de ensino e aprendizagem em diversos níveis de ensino. Nesta perspectiva, o autor, afirma que a maneira e a forma de como caracterizar o ensino para ocorrer a aprendizagem se constitui em um desafio que se encontra em aberto.

Edel Alexandre Silva Pontes intenciona no texto "Noção intuitiva no ato de ensinar e aprender matemática por meio de uma atividade de ensino de sistemas lineares com coeficientes positivos", ressignificar um modelo escolar com responsabilidade pedagógica, alocando o educando como ator de suas aprendizagens, um investigador crítico e conectado com suas realidades e atributos. Assim, o autor parte da concepção de que as dificuldades na compreensão de conceitos matemáticos na Educação Básica são evidentes no desempenho escolar dos educandos, especialmente pelas propostas educacionais suplantadas e que não conseguem aproximar nenhum interesse do aprendiz pelos conteúdos recomendados. E por fim, deixa claro que seu objetivo é afrontar as inquietudes de pesquisadores da Educação Matemática, estabelecendo três pressupostos indispensáveis para minimizar questionamentos sobre o ensino e aprendizagem de matemática, que são: Problema, Causa e Paradigma.

"Dramatemática: Teatro e Matemática", sexto artigo desse volume e de autoria de Vinícius Borovoy de Sant'ana e Maria Beatriz Porto, articula o Teatro com a Educação Matemática a partir da elaboração de um curso de extensão. Visando o desenvolvimento da pesquisa, os autores procuraram responder ao seguinte questionamento: Como a articulação do Teatro e da Matemática, a partir dos jogos teatrais e/ou dramáticos, pode contribuir para a formação de professores de Matemática atuantes nos anos iniciais? Buscando responder ao questionamento, foram aplicadas atividades de linguagem teatral e propostas situações nas quais a Matemática foi apresentada de forma viva e contextualizada. 


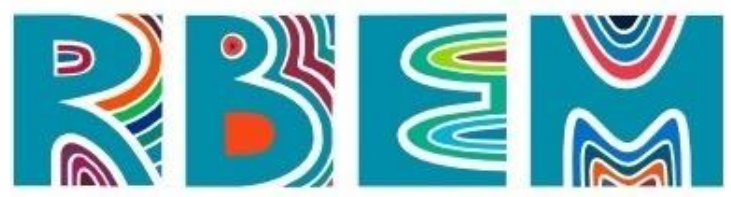

REVISTA BAIANA DE EDUCAÇÃO MATEMÁTICA

No cenário educacional contemporâneo tem sido uma recorrência enveredar por discussões que considerem o ensino e a aprendizagem como processos que se transversalizam por uma educação contextualizada. Partindo dessa premissa Fabrício Oliveira da Silva e Charles Maycon de Almeida Mota, no texto "Trigonometrizando na roça: Implicações de uma Educação Matemática contextualizada”, apresentam uma reflexão embasada na experiência com o desenvolvimento de práticas docentes em espaços não formais com o intuito de vivenciar os processos de planejamento e avaliação referentes à área da Matemática, utilizando a contextualização de conteúdos para possibilitar aos estudantes, que moram em áreas rurais, uma experiência que desencadeie o desenvolvimento de uma aprendizagem significativa. O texto reflete os contextos da roça, evidenciando como isso pode ser potencializado como lócus para valorização de fazeres na docência que extrapolem os muros da escola e se ampliem pelos contextos de vida de seus estudantes.

O oitavo texto intitulado "Conhecimento matemático para o ensino através do Estado da Arte envolvendo Números Racionais em pesquisas brasileiras", de autoria de Paulo César Oliveira, Beatriz. Zero e Reynaldo D’Alessandro Neto teve por objetivo apresentar, a partir de um levantamento envolvendo teses e dissertações, como o referencial do Conhecimento Matemático para o Ensino foi mobilizado em investigações sobre números racionais. A busca foi efetivada em dois bancos de dados, a Biblioteca Digital Brasileira de Teses e Dissertações e o Catálogo de Teses e Dissertações da CAPES.

Gevando Lopes Santos e Américo Junior Nunes da Silva objetivaram no texto intitulado "O Laboratório de Estudos e Pesquisas em Educação Matemática e a construção de material didático: o "Semelhâmetro" e o ensino de semelhança de triângulos", relatar a experiência que tiveram com o processo de criação e validação de um material didático nomeado "Semelhâmetro", bem como apresentar suas características e passo a passo de sua utilização. Os autores destacam ainda que, esse material foi construído no Laboratório de Estudos e Pesquisas em Educação Matemática do Departamento de Educação da Universidade do Estado da Bahia, campus VII, e possibilita a realização de cálculos de distâncias sem a utilização de instrumentos de medidas, tais como fita métrica, trena, etc.

Esperamos com mais este número poder contribuir com o fomento das pesquisas no campo da Educação Matemática ampliando o diálogo entre os professores e pesquisadores. Assim, diante de toda essa apresentação, convidamos a você querido leitor a mergulhar 


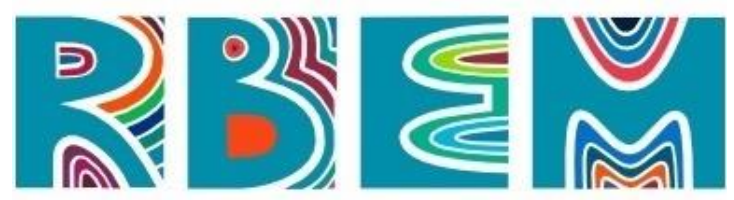

REVISTA BAIANA DE EDUCAÇÃO MATEMÁTICA

conosco nas teias reflexivas desses escritos a fim de poder contribuir com novas pesquisas e desta forma amplificar os estudos e consequentemente o conhecimento na área da Educação Matemática.

Boa leitura!

\section{Referências}

ATAIDE, C. R. de; COSTA, W. C. L. da. Formação de Professores: O estado do conhecimento no ensino de fração para estudantes surdos. Revista Baiana de Educação Matemática, v. 2, n. 01, p. 01-22, e202102, 3 fev. 2021. DOI: 10.47207/rbem.v2i01.10667

ANDRADE, S. V. R.; BEZERRA, R. C.; CAETANO, R. S. Estágio Curricular Supervisionado na Pandemia da Covid-19: (Re) pensando a formação inicial do professor de Matemática. In: Revista Baiana de Educação Matemática, v. 02, n. 01, p. 01/20, e202122, jan./dez., 2021. DOI: 10.47207/rbem.v2i01.12397.

ARAUJO, A. S.; SOUZA, P. N.; PORTO NASCIMENTO, A. M. Oficinas de Matemática no Projeto Social Cata-Vento: uma prática em Educação Não Formal. In: Revista Baiana de Educação Matemática, v. 02, n. 01 p. 01-20, e202128, jan./dez., 2021. DOI: 10.47207/rbem.v2i01.12086.

ARAÚJO, H. M. C.; MARIN, D.; SOUZA JUNIOR, A. J. Estágio Supervisionado na formação de professores de Matemática, na modalidade à distância: reflexos da pandemia. In: Revista Baiana de Educação Matemática, v. 02, n. 01, p. 01-25, e202132, jan./dez., 2021. DOI: $10.47207 /$ rbem.v2i01.12367.

ARAÚJO, M. L. H. S.; GRILO, J. S. P. Reconfigurando o Estágio Curricular Obrigatório em Matemática para o Contexto de Ensino Remoto Emergencial. In: Revista Baiana de Educação Matemática, v. 02, n. 01, p. 01-25, e202111, jan./dez., 2021. DOI: 10.47207/rbem.v2i01.12146.

BARBOZA, P. L. Depoimentos de alunos concluintes de uma licenciatura sobre o processo de ensino e aprendizagem. Revista Baiana de Educação Matemática, v. 2, n. 01, p. 01-15, e202104, 8 mar. 2021. DOI: 10.47207/rbem.v2i01.10206.

BOROVOY DE SANT'ANA, V.; PORTO, M. B. Dramatemática: Teatro e Matemática. Revista Baiana de Educação Matemática, v. 2, n. 01, p. 01-19, e202107, 7 ago. 2021. DOI: 10.47207/rbem.v2i01.11984.

BRAGA, M. D.; PINA NEVES, R. S.; MENDONÇA, M. P. N.; OLIVEIRA, C. F. B. O Estágio Curricular Supervisionado e o Ensino Remoto: percepções de futuros professores de matemática. In: Revista Baiana de Educação Matemática, v. 02, n. 01, p. 01-25, e202130, jan./dez., 2021. DOI: 10.47207/rbem.v2i01.12765. 


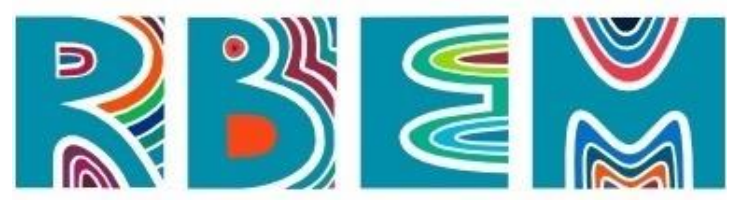

REVISTA BAIANA DE EDUCAÇÃO MATEMÁTICA

BURIGATO, S. M. M. S.; SANTOS, C. M.. Condições e restrições do estágio supervisionado no ensino remoto, no curso de Matemática - Licenciatura Da UFMS. In: Revista Baiana de Educação Matemática, v. 02, n. 01, p. 01-24, e202124, jan./dez., 2021. DOI: 10.47207/rbem.v2i01.12389.

CHAGAS, I. B.; FERREIRA, A. R. C. Vivências no ensino de Álgebra no $7^{\circ}$ ano em contexto remoto a partir de uma experiência no Estágio Supervisionado. In: Revista Baiana de Educação Matemática, v. 02, n. 01, p. 01-26, e202114, jan./dez., 2021. DOI:

10.47207/rbem.v2i01.12311.

FELCHER, C. D. O.; FERREIRA, A. L. A. O estágio curricular supervisionado na compreensão de licenciados : Perspectivas, Desafios e Aprendizagens. In: Revista Baiana de Educação Matemática, v.02, n.01, p. 01-20, e202112, jan./dez., 2021. DOI: 10.47207/rbem.v2i01.12392.

FIORENTINI, D.; PINA NEVES, R. da S.; BRAGA, M. D.; SILVA, A. J. N. da; VIEIRA, A. R. L. O Estágio Curricular Supervisionado em Matemática nos contextos de ensino presencial, remoto e híbrido - Dossiê Temático. Revista Baiana de Educação Matemática, v. 2, n. 01, p. 01-09, e202100, 7 dez. 2021. DOI: 10.47207/rbem.v2i01.13318.

JULIO, R. S.; LIMA, D. C. Produções de conhecimento a partir do estágio de forma remota no Ensino Médio em Minas Gerais. In: Revista Baiana de Educação Matemática, v. 02, n. 01, p. 01-20, e202120, jan./dez., 2021., DOI: 10.47207/rbem.v2i01.11996.

LIMA, A. C. S.; BARBOSA, P. L. Estágio Supervisionado como espaço de aprendizagem na licenciatura em Matemática. In: Revista Baiana de Educação Matemática, v. 02, n. 01, p. 01/19, e202123, jan./dez., 2021., DOI: 10.47207/rbem.v2i01.12017.

LIMA, F. J.; SILVA, R. Para além das aparências: desafios e percepções diante da oferta do Estágio Supervisionado na Licenciatura em Matemática do IFCE campus Cedro no contexto do ensino remoto. In: Revista Baiana de Educação Matemática, v. 02, n. 01, p. 01-20, e202109, jan./dez., 2021. DOI: 10.47207/rbem.v2i01.12370.

MARTINS, P. B. M.; NASCIMENTO, J. C. P.; CARVALHO, J. G. Conhecimentos e aprendizagens produzidas e mobilizadas por futuros professores em uma disciplina de Estágio Possibilidades no Contexto Pandêmico. In: Revista Baiana de Educação Matemática, v. 02, n. 01 p. 01-24, e202127, jan./dez., 2021. DOI: 10.47207/rbem.v2i01.12132.

MENDUNI-BORTOLOTI, R. D’ A.; OLIVEIRA, K. V. G. A Resolução de Problemas enquanto metodologia de ensino no Estágio Remoto Emergencial. In: Revista Baiana de Educação Matemática, v. 02, n. 01, p. 01-23, e202133, jan./dez., 2021. DOI: 10.47207/rbem.v2i01.12159.

MIOLA, A. F. S.; JORGE, N. M.; PEREIRA, P. S. Estágio Supervisionado em Matemática e a Espiral Formativa: uma experiência vivenciada em aulas presenciais e remotas. In: Revista 


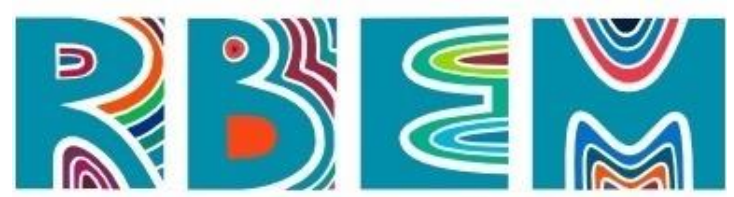

REVISTA BAIANA DE EDUCAÇÃO MATEMÁTICA

Baiana de Educação Matemática, v. 02, n. 01, p. 01-19, e202125, jan./dez., 2021. DOI: 10.47207/rbem.v2i01.12400.

OLIVEIRA, P. C.; ZERO, B.; D’ALESSANDRO NETO, R. Conhecimento matemático para o ensino através do Estado da Arte envolvendo Números Racionais em pesquisas brasileiras. Revista Baiana de Educação Matemática, v. 2, n. 01, p. 01-23, e202121, 28 set. 2021. DOI: $10.47207 /$ rbem.v2i01.12450.

PINA NEVES, R. S.; BRAGA, M. D.; FIORENTINI, D. Estágio Curricular Supervisionado em Matemática em Processo de Lesson Study on-line: adaptações, desafios e inovações. In: Revista Baiana de Educação Matemática, v. 02, n. 01, p. 01-31, e202135, jan./dez., 2021. DOI: 10.47207/rbem.v2i01.13139.

PIRES, M. A. L. M.; MENDES, I. A. Estágio Supervisionado na Formação Inicial de Professores de Matemática: limites e possibilidades. In: Revista Baiana de Educação Matemática, v. 02, n. 01, p. 01-22, e202113, jan./dez., 2021. DOI: 10.47207/rbem.v2i01.12166.

PONTES, E. A. S. Noção intuitiva no ato de ensinar e aprender matemática por meio de uma atividade de ensino de sistemas lineares com coeficientes positivos. Revista Baiana de Educação Matemática, v. 2, n. 01, p. 01-15, e202106, 26 maio 2021. DOI: 10.47207/rbem.v2i01.11286.

PROENÇA, M. C.; MENDES, L. O. R.; OLIVEIRA, A. B. Estágio Curricular Supervisionado no Contexto do Ensino Remoto: análise da visão de futuros professores de Matemática. In: Revista Baiana de Educação Matemática, v. 02, n.1, p. 01-21, e202108, jan./dez., 2021. DOI: 10.47207/rbem.v2i01.11965.

SANTOS, M. R. DOS; DEODATO, A. A. Estágio Remoto de Matemática: o que se mostra além da tela plana? . Revista Baiana de Educação Matemática, v. 2, n. 01, p. e202129, 7 dez. 2021. DOI: $10.47207 /$ rbem.v2i01.12398.

SANTOS, J.; MOREIRA, J.; DA SILVA, J. N. D. Uma Experiência de Estágio Supervisionado no Ensino Remoto: Um trabalho com a cesta básica. Revista Baiana de Educação Matemática, v. 2, n. 01, p. e202115, 7 dez. 2021. DOI: 10.47207/rbem.v2i01.12395.

SANTOS, I. S. G.; SILVA, J. M. B.; CEDRO, W. L. Aprendendo a ensinar Matemática no Ensino Remoto. In: Revista Baiana de Educação Matemática, v. 02, p. 01-20, e202119, jan./dez., 2021. DOI: 10.47207/rbem.v2i01.12157.

SANTOS, G. L.; SILVA, A. J. N. da. O Laboratório de Estudos e Pesquisas em Educação Matemática e a construção de material didático: o "Semelhâmetro" e o ensino de semelhança de triângulos. Revista Baiana de Educação Matemática, v. 2, n. 01, p. 01-16, e202105, 19 abr. 2021. DOI: 10.47207/rbem.v2i01.11334. 


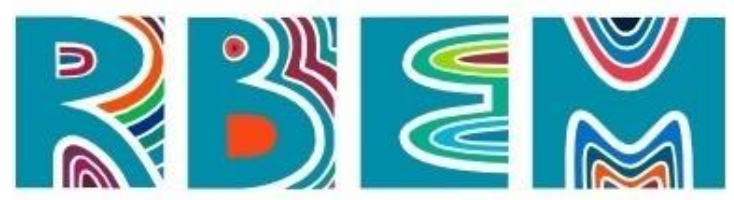

REVISTA BAIANA DE EDUCAÇÃO MATEMÁTICA

SILVA, F. M.; BORELLI, S. S.. O Estágio Supervisionado na Formação Inicial do Professor: A experiência em uma escola municipal de São Paulo e os seus desafios em Tempos Pandêmicos. In: Revista Baiana de Educação Matemática, v. 02, p. 01-19, e202117, jan./dez., 2021. DOI: $10.47207 /$ rbem.v2i01.12320.

SILVA, F. O. da; MOTA, C. M. de A. Trigonometrizando na roça: Implicações de uma Educação Matemática contextualizada. Revista Baiana de Educação Matemática, v. 2, n. 01, p. 01-20, e202116, 10 set. 2021. DOI: 10.47207/rbem.v2i01.12502.

SILVA, U. D. da; OLIVEIRA, A. T. C. C. de. Influências do Estágio Supervisionado para Professores de Matemática em Início de Carreira - buscando compreender escolhas e características das escolas-campo. Revista Baiana de Educação Matemática, v. 2, n. 01, p. 0125, e202101, 18 jan. 2021. DOI: 10.47207/rbem.v2i01.10252.

SOUZA, R. M. de; SOUZA, I. DOS S. de; LIMA, R. F. Entendimentos de professores que ensinam matemática sobre a relação entre jogo e raciocínio lógico. Revista Baiana de Educação Matemática, v. 2, n. 01, p. 01-21, e202103, 8 fev. 2021. DOI: 10.47207/rbem.v2i01.10212.

SOUZA, J. C. S. DE; SOARES, W. M. Estágio Supervisionado na formação inicial do docente de matemática no contexto do ensino remoto: reflexões sobre a experiência do Instituto Federal de Brasília - Campus Estrutural. Revista Baiana de Educação Matemática, v. 2, n. 01, p. e202134, 7 dez. 2021. DOI: 10.47207/rbem.v2i01.12375.

TAVEIRA, F. A. L.; SILVA, S. R. V. O Estágio Digital Supervisionado em um curso de Licenciatura em Matemática no interior do Estado de São Paulo: uma narrativa problematizada. In: Revista Baiana de Educação Matemática, v. 02, n. 01, p. 01-17, e202131, jan./dez., 2021. DOI: 10.47207/rbem.v2i01.12385.

VIANA, D. S. B.; MENDUNI-BORTOLOTI, R. D’A. Estágio Supervisionado contribuindo com o processo formativo de uma mestranda em estágio de docência na pandemia. In: Revista Baiana de Educação Matemática, v. 02, p. 01-22, e202118, jan./dez., 2021. DOI: 10.47207/rbem.v2i01.12165.

ZAMPIERI, M. T.; SOUSA, M. C.; GAMA, R. P. O estágio supervisionado compartilhado de matemática no contexto pandêmico: ações do movimento de uma política institucionalizada. In: Revista Baiana de Educação Matemática, v. 02, n. 01, p. 01-25, e202126, jan./dez., 2021. DOI: $10.47207 /$ rbem.v2i01.12225.

ZANON, Thiarla Xavier Dal-Cin. Entre Lives, Textos e Contextos: o Estágio Supervisionado na EJA em Tempos de Ensino Remoto. In: Revista Baiana de Educação Matemática, v. 03, n. 01, p. 01-28, e202110, jan./dez., 2021. DOI: 10.47207/rbem.v2i01.12130. 